CLINICAL STUDY

\title{
The relationship of active ghrelin levels and intrauterine growth in preterm infants
}

\author{
Hamilcikan Sahin $^{1}$, Tugba Erener ${ }^{1}$, Ethem Erginoz ${ }^{2}$, Mehmet Vural $^{1}$, Barbaros Ilikkan ${ }^{1}$, Sultan Kavuncuoglu ${ }^{3}$, \\ Hayrettin Yildiz ${ }^{1}$ and Yildiz Perk ${ }^{1}$ \\ Departments of ${ }^{1}$ Neonatology and ${ }^{2}$ Public Health, Cerrahpasa Medical Faculty, Istanbul University, Istanbul, Turkey and ${ }^{3}$ Department of Neonatology, \\ Bakırkoy Maternity and Children Hospital, Istanbul, Turkey \\ (Correspondence should be addressed to T Erener who is now at Libadiye Cad. Göztepe Soyak Sitesi, Block 37, No. 688 Göztepe/Üsküdar, Istanbul, Turkey; \\ Email: tugbaerener@yahoo.com)
}

\begin{abstract}
Objective: We examined the association of active ghrelin levels with birth weight, sex, and gestational age (GA) in small for GA (SGA) and appropriate for GA (AGA) preterm infants.

Methods: Active ghrelin levels were measured by ELISA method during the first five postnatal days in 38 preterm SGA infants and 32 preterm AGA controls.

Results: Active ghrelin levels were significantly higher in preterm SGA infants than in preterm AGA controls $(P<0.01)$. Active ghrelin levels in preterms with birth weight $<1500 \mathrm{~g}$ were statistically higher than those over $1500 \mathrm{~g}$. Active ghrelin levels in preterms $\leq 34$ gestational weeks were similar to those over 34 weeks. A negative correlation was detected between active ghrelin levels and birth weight $(r=-0.561, P<0.0001)$ as well as GA $(r=-0.449, P<0.0001)$.

Conclusion: We found significantly higher active ghrelin levels in SGA preterms than those in AGA preterms and demonstrated a negative correlation between active ghrelin levels and birth weight in preterm infants. This was the first study showing a negative correlation between active ghrelin levels and birth weight in preterm infants.
\end{abstract}

European Journal of Endocrinology 166 399-405

\section{Introduction}

Ghrelin is a 28-amino residue peptide predominantly produced by the stomach whereas lower amounts are derived from the hypothalamus, kidney, heart, pancreatic cells, and the placenta (1). It is a natural ligand of the $\mathrm{GH}$ secretagogue receptor type 1a that stimulates the release of GH. For its biological function, ghrelin has to be acylated by $n$-octanoic acid at one of its serine residues. Although the most active form of ghrelin is the octanoylated form, the majority (80-90\%) of circulating ghrelin has been found to be in the nonacylated form, which does not exert any endocrine action (2). Ghrelin has orexigenic effects generating a positive energy balance by reducing fat oxidation promoting adiposity and by increasing appetite $(1,3)$.

However, the physiological role of ghrelin in newborn babies is not clear (4). Knockout animal studies propose that ghrelin is not required for fetal and early postnatal growth under normal nutritional conditions $(5,6,7)$. Current ghrelin and ghrelin $\mathrm{O}$-acyltransferase knockout models suggest that ghrelin plays a minimal role in food intake and body weight and that ghrelin is a key modulator of energy metabolism during negative energy balance with an essential role in blood glucose control during starvation $(8,9)$.

Ghrelin can be detected in fetal circulation from 20 to 23 weeks of gestation (10). Previous studies measured total ghrelin levels in the cord blood and in the postnatal period, and associations between circulating ghrelin levels and anthropometric and hormonal parameters have been documented by some studies but not by others $(11,12,13)$. The levels of active ghrelin in newborns have recently been investigated (13).

The objective of this study was to examine the association of active ghrelin levels with birth weight, sex, and gestational age (GA) in small for GA (SGA) and appropriate for GA (AGA) preterm infants in the first 5 days of life.

\section{Materials and methods}

A total of 70 premature infants between 24 and 37 weeks of gestation who had been admitted to the neonatal intensive care unit of Cerrahpasa Medical 
Faculty and Istanbul Ministry of Health Bakirkoy Maternity Teaching Hospital were included in the study. Infants with major congenital abnormalities, severe asphyxia or infection, and infants from multiple pregnancies were excluded from the study. Informed consent was obtained from the parents of study infants and the study was approved by the Ethics Committee of Cerrahpasa Medical Faculty, Istanbul University.

Study infants were divided into two groups. Group 1 included 38 preterm infants ( 24 females and 14 males) who were SGA. Group 2 included 32 premature infants (14 females and 18 males) who were AGA.

SGA infants were defined as having a birth weight below the 10th percentile. AGA infants were defined as having a birth weight between the 10th and the 90th percentile on the intrauterine growth charts of Lubchenco et al. (14). As national intrauterine growth curves are not available, curves described by Lubchenco et al. (14) were used.

GA was estimated from the last menstrual period of the mother and was re-evaluated by the New Ballard Scoring system (15) by an experienced neonatologist. Infants whose estimated GA was in accordance with the GA determined by the New Ballard Scoring system were included in the study if they were between 24 and 37 weeks of gestation.

Feeding with breast milk was typically initiated within the first $12 \mathrm{~h}$ after birth with a volume of $20 \mathrm{ml} / \mathrm{kg}$ divided over eight feedings per day. When breast milk was unavailable, a cow milk-based premature formula (Prematil, Milupa Nutricia S.A.S, Fulda, Germany) was used. Increments of $10 \mathrm{ml} / \mathrm{kg}$ per day in total feeding volume were made each day according to the tolerance of the baby after the first day of initiation of feeding.

In the AGA group, $11(34.3 \%)$ of the preterms suffered from respiratory distress syndrome, three $(9.4 \%)$ had intraventricular hemorrhage, and two $(6.3 \%)$ had early sepsis, whereas in the SGA group, the associated illnesses were seen in 12 (31.6\%), two $(5.3 \%)$, and one $(2.6 \%)$ of the subjects.

Two milliliters of venous blood sample were obtained from the study groups during the first five postnatal days immediately before feeding in the morning and were transferred into tubes containing EDTA $(1.25 \mathrm{mg} / \mathrm{ml})$ and aprotinin $(500 \mathrm{U} / \mathrm{ml})$. The blood collection was scheduled to coincide with the clinical blood sampling procedure in order to avoid any disturbance to the infant. Blood samples were centrifuged at relative centrifugal force (RCF) of $1500 \mathrm{~g}$ at $4^{\circ} \mathrm{C}$ for $15 \mathrm{~min}$. Active (acylated form) ghrelin is unstable in blood and easily reverts to nonacylated inactive form. So, separated plasma after centrifugation was acidified with $1 \mathrm{~N} \mathrm{HCl}$ ( $1: 10$ relative to the plasma volume) to stabilize octanoyl modification and stored at $-80{ }^{\circ} \mathrm{C}$ until analysis.

Active ghrelin levels were measured by ELISA method with LINCO-Active Ghrelin ELISA kit (catalogue number EZGAC-86K, Linco Research, St Charles, MO, USA).

\section{Statistical analysis}

Mann-Whitney $U$ test was used to compare differences between groups. Correlation between ghrelin levels and several anthropometric measures was done using the Pearson correlation test. $\chi^{2}$ test was used for comparison of categorical variables. Analysis of covariance (ANCOVA) was used to compare ghrelin level between groups controlling for estimated confounding factors. $P$ values $<0.05$ were considered statistically significant.

\section{Results}

Study subjects consisted of 70 preterm infants between 24 and 37 weeks of GA. Characteristics of the study population are summarized in Table 1.

Female infants were heavier than male infants (1549 $+284 \mathrm{~g}$ (range: $1030-2240 \mathrm{~g})$ vs $1801 \pm 409 \mathrm{~g}$ (range: 930-2700 g), $P<0.01$ ) with similar GAs $(33.7 \pm 1.9$ vs $34.3 \pm 1.9$ weeks, $P=0.204)$. There were no sex differences in the mode of delivery.

Ghrelin levels were similar between females and males (135.2 \pm 27.9 vs $124.7 \pm 27.3 \mathrm{pg} / \mathrm{ml}, P=0.119)$.

The SGA group consisted of $38(45.7 \%)$ infants and AGA group consisted of $32(54.3 \%)$ infants. Mean birth weight of AGA infants was $1843 \pm 383 \mathrm{~g}$ (range: 1060-2700 g) while mean birth weight of SGA infants was $1513 \pm 277 \mathrm{~g}$ (range: 930-1980 g).

There was no statistical difference between groups with regard to sex and GA.

The mean time at which blood samples were obtained after birth was $3.1 \pm 1.4$ (range: $1-5$ ) days in AGA group and 3.2 \pm 1.4 (range: $1-5$ days) in SGA group, which was statistically insignificant. There was also no statistical difference in mean ghrelin levels with regard to sampling day according to the Kruskal-Wallis test $(P=0.963$; Table 2).

There were no differences in postnatal nutritional state including the amount of milk intake per body weight and type of feedings (breast milk vs formula) between SGA and AGA groups. There was also no difference in the associated illness pattern between SGA and AGA infants. Characteristics of AGA and SGA groups and ghrelin levels are summarized in Table 1.

The mean plasma active ghrelin concentrations were $117.5 \pm 25.3 \mathrm{pg} / \mathrm{ml}$ (range: 72.8-173.3) and $141.3 \pm 25.6 \mathrm{pg} / \mathrm{ml}$ (range: 95.1-191.4) in AGA and SGA groups respectively. Plasma active ghrelin concentration was significantly higher in SGA group than that in AGA group $(P<0.001)$.

Active ghrelin concentration in SGA female and male infants was also significantly higher than that in AGA females and males.

To exclude the influence of gender and GA on active ghrelin level in SGA and AGA infants, we compared the active ghrelin level of these two groups after controlling for gender and GA by using ANCOVA. Active ghrelin 
Table 1 Demographic features of the study population and characteristics of appropriate for gestational age (AGA) and small for gestational age (SGA) groups.

\begin{tabular}{|c|c|c|c|c|c|c|c|}
\hline & \multirow[b]{2}{*}{$n$} & \multirow[b]{2}{*}{ Percentage (\%) } & \multicolumn{2}{|r|}{ AGA } & \multicolumn{2}{|r|}{ SGA } & \multirow[b]{2}{*}{$P$} \\
\hline & & & $n$ & Ghrelin & $n$ & Ghrelin & \\
\hline \multicolumn{8}{|l|}{ Sex } \\
\hline Female & 38 & 54.3 & 14 & $122.8 \pm 27.0(79.6-173.3)$ & 24 & $142.4 \pm 26.4(95.1-191.4)$ & $0.046^{*}$ \\
\hline Male & 32 & 45.7 & 18 & $113.3 \pm 23.7(72.8-157.4)$ & 14 & $139.3 \pm 25.0(97.9-186.8)$ & $0.008^{*}$ \\
\hline \multicolumn{8}{|l|}{ Mode of delivery } \\
\hline Vaginal & 21 & 30.0 & 10 & $116.5 \pm 20.1(89.8-146.5)$ & 11 & $151.8 \pm 26.3(99.6-191.4)$ & $0.005^{\star}$ \\
\hline $\mathrm{C} / \mathrm{S}$ & 49 & 70.0 & 22 & $117.9 \pm 27.7(72.8-173.3)$ & 27 & $137.3 \pm 24.7(95.1-186.9)$ & $0.023^{*}$ \\
\hline \multicolumn{8}{|l|}{ Birth weight } \\
\hline$<1500 \mathrm{~g}$ & 20 & 28.6 & 4 & $147.4 \pm 8.6(136.6-157.4)$ & 16 & $147.3 \pm 32.5(97.9-191.4)$ & 0.750 \\
\hline$\geq 1500 \mathrm{~g}$ & 50 & 71.4 & 28 & $113.2 \pm 23.9(72.8-173.3)$ & 22 & $136.8 \pm 18.7(95.1-170.9)$ & $0.001^{*}$ \\
\hline \multicolumn{8}{|l|}{ Gestational age } \\
\hline$\leq 34$ weeks & 36 & 51.4 & 20 & $123.9 \pm 24.5(79.6-173.3)$ & 16 & $149.9 \pm 32.5(95.1-191.4)$ & $0.020^{\star}$ \\
\hline$>34$ weeks & 34 & 48.6 & 12 & $106.9 \pm 23.8(72.8-146.5)$ & 22 & $135.0 \pm 17.4(99.6-170.9)$ & $0.001^{*}$ \\
\hline
\end{tabular}

C/S, Caesarian section; ${ }^{*} P<0.05$.

level was still significantly higher in the SGA group after controlling for gender and GA (Table 3).

In order to determine active ghrelin level in very low birth weight infants and compare it with that of low birth weight infants, we divided our cohort into two groups: those $<1500 \mathrm{~g}$ and those $\geq 1500 \mathrm{~g}$. Preterms weighing $<1500 \mathrm{~g}$ had a higher mean active ghrelin concentration $(147.3 \pm 29.1 \mathrm{pg} / \mathrm{ml})$ compared with those weighing $>1500 \mathrm{~g} \quad(123.6 \pm 24.6 \mathrm{pg} / \mathrm{ml}$, $P=0.001$ ).

To compare the active ghrelin level in the late preterm period with that of the early preterm period, we again divided our cohort into two groups according to GA: those $<34$ weeks and those between 34 and 37 weeks. Early preterms had similar mean active ghrelin concentrations $(135.4 \pm 30.8 \mathrm{pg} / \mathrm{ml})$ as in late preterms (125.6 $23.8 \mathrm{pg} / \mathrm{ml}, P=0.121)$.

When we compared active ghrelin levels between AGA and SGA infants constituting the mentioned groups above, there was no statistical difference in active ghrelin concentrations between AGA and SGA infants with a birth weight $<1500 \mathrm{~g}$ while SGA infants $\geq 1500$ g had statistically higher active ghrelin concentrations than AGA infants $\geq 1500 \mathrm{~g}$. Active ghrelin concentrations were also significantly higher in SGA infants with both GAs of $\leq 34$ and $>34$ weeks than those of AGA infants with both GAs of $\leq 34$ and $>34$ weeks.

A negative correlation was detected with birth weight and plasma active ghrelin level $(r=-0.561$, $P<0.0001$; Fig. 1). There was also a negative correlation between GA and plasma active ghrelin level detected using the Pearson correlation test $(r=-0.449, P<0.0001$; Fig. 2).

\section{Discussion}

There are a limited number of studies evaluating the levels of active ghrelin in preterm infants in the immediate postnatal period and its relationship with certain anthropometric measures. In the current study, we evaluated plasma active ghrelin levels in the immediate postnatal period in SGA and AGA preterm infants to demonstrate any relationship between active ghrelin levels and birth weight, sex, and GA.

We found no statistical difference in ghrelin levels between female and male preterm infants. This was in accordance with the studies measuring total and/or active ghrelin levels in full-term and/or preterm infants $(16,17,18,19,20,21)$. Only in the study by Onal et al. (12) were greater values of total ghrelin found in female than in male infants in the SGA group. In this study, we also found no difference in active ghrelin levels between genders in the SGA group (data not shown).

Active ghrelin was inversely related to GA in these premature infants. This finding was in contradiction to other reports. In the study by $\mathrm{Ng}$ et al. (16), no significant correlation was found between plasma total ghrelin and GA, leading to the hypothesis that ghrelin secretion might not show any GA-related variations. In this study, total ghrelin was obtained within the first $2 \mathrm{~h}$ of life in 40 term (37-42 weeks of gestation) and 81 preterm infants (23-36 weeks of gestation). In the study by Yokota et al. (22), venous cord blood samples were obtained from 54 full-term and five premature infants with a GA of 30.6-35.3 weeks. Although a positive correlation was not found between GA and total ghrelin

Table 2 Ghrelin levels with regard to day of blood sampling.

\begin{tabular}{lcccc}
\hline $\begin{array}{l}\text { Day of } \\
\text { blood } \\
\text { sampling }\end{array}$ & $\begin{array}{c}\text { Number of } \\
\text { subjects }\end{array}$ & $\begin{array}{l}\text { Mean ghrelin } \\
\text { levels }(\mathrm{pg} / \mathrm{ml})\end{array}$ & s.D. & $\boldsymbol{P}^{\mathrm{a}}$ \\
\hline 1 & 12 & 131.07 & \pm 25.46 & 0.963 \\
2 & 14 & 133.49 & \pm 16.28 & \\
3 & 14 & 125.65 & \pm 30.23 & \\
4 & 13 & 133.97 & \pm 30.83 & \\
5 & 17 & 128.55 & \pm 34.72 & \\
\hline
\end{tabular}

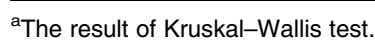


Table 3 Analysis of covariance table showing a significant difference in active ghrelin level between groups corrected for gender and gestational age.

\begin{tabular}{lrl}
\hline & $\boldsymbol{F}$ & \multicolumn{1}{c}{$\boldsymbol{P}$} \\
\hline Group & 34.806 & 0.0001 \\
Gender & 0.020 & 0.889 \\
Gender $\times$ group & 0.577 & 0.450 \\
Gestation & 37.806 & 0.0001 \\
\hline
\end{tabular}

concentrations, they found a positive correlation between GA and active ghrelin concentration and suggested that $n$-octanoylation system could undergo maturational changes during gestation or active ghrelin could be degraded relatively earlier during earlier GAs. However, the sample size for premature infants was very small in this study. Bellone et al. (11) reported a clear positive association between cord blood ghrelin levels and GA in a cohort of 117 newborns (24 preterm and 94 term infants). However, in the other three studies by Lanyi et al. (17), Martos-Moreno et al. (21), and Shizimizu et al. (23) that evaluated active ghrelin concentrations in preterm infants as in our study, no correlation was observed between active ghrelin levels and GA. Cord blood levels of active ghrelin were determined in 99 and 26 preterm infants, in the study by Martos-Moreno et al. (21) and Lanyi et al. (17), respectively, while Shizimizu et al. (23) investigated the levels of active ghrelin in 25 preterm infants not only in cord blood but also in venous blood samples at birth and $2,4,6$, and 8 weeks of age. In these latter studies, the study cohort also constituted the preterm infants but the sampling time for determination of active ghrelin was different from that of our study, which might have contributed to the contradiction between our study and those.

Acylated form of ghrelin (active ghrelin), which is the biologically active form, has been recently investigated to assess whether it has a role in fetal and neonatal growth. The exact role of active ghrelin in intrauterine life is still unknown. There has been an ongoing debate concerning the relationship between ghrelin and anthropometric parameters at birth. Some studies demonstrate an association while others do not $(11,12$, 13, 20, 24). In our study, a negative correlation was detected with birth weight and plasma active ghrelin levels. Active ghrelin concentration was found to be significantly higher in SGA infants than that in AGA infants, and this difference still remained significant after controlling for gender and GA. Infants with birth weight $<1500 \mathrm{~g}$ also had significantly higher active ghrelin concentration than that of infants with birth weight over $1500 \mathrm{~g}$. This might be due to the higher percentage of SGA infants constituting the group with birth weight $<1500 \mathrm{~g}$ than the group with birth weight over $1500 \mathrm{~g}$ ( $80 \%$ SGA infants vs $44 \%$ AGA infants). Comparable ghrelin concentrations without any statistical significance between SGA and AGA infants in the group constituting infants with birth weight $<1500 \mathrm{~g}$ could be explained by the small sample size of the AGA infants in this group (16 SGA infants vs four AGA infants).

The first report demonstrating that the cord blood concentration of ghrelin in SGA infants was higher than that in AGA infants was by Onal et al. (12). This study was conducted in term infants and measured only total ghrelin levels. In another study including term infants and measuring total ghrelin, Kitamura et al. (13) found that ghrelin concentration in SGA newborns was significantly higher than that in AGA and large for gestational age (LGA) newborns. In the study by Mendez-Ramirez et al. (25), total ghrelin was significantly higher in full-term SGA babies after a week of age, and birth weight was found to be associated negatively with total ghrelin levels. However, Kyriakakou et al. (24) demonstrated that total ghrelin levels in the cord blood and at postnatal days 1 and 4 had not differed between term SGA and AGA neonates.

When other studies measuring total ghrelin levels in a study population of both term and preterm infants were reviewed, ghrelin levels correlated negatively with anthropometric variables in full-term newborns and postnatally, but not in preterm newborns as in the study by Soriano-Guillen et al. (18). In the study by Farquhar et al. (19), cord ghrelin concentrations were higher in SGA compared with AGA/LGA neonates when the whole group of term and preterm neonates was included. In this study, preterm and full-term neonates were not studied separately. In the study by $\mathrm{Ng}$ et al. (16), plasma ghrelin level within the first $2 \mathrm{~h}$ of life was significantly and inversely correlated with birth weight only in the term infant group with the lack of any correlation in the preterm infant group and led the authors to the hypothesis that ghrelin might adopt its

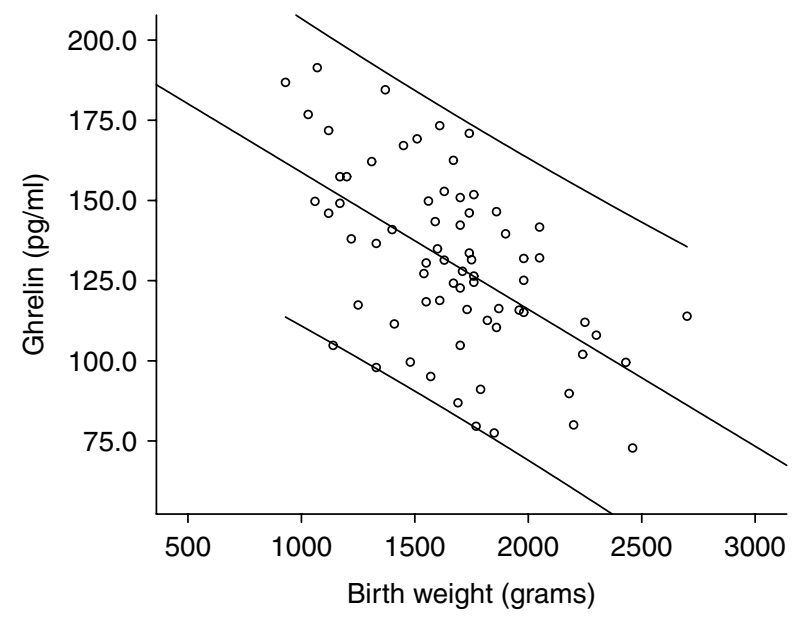

Figure $1 \mathrm{~A}$ negative correlation between active ghrelin level and birth weight using the Pearson correlation test $(r=-0.561$, $P<0.0001)$. The middle line represents the linear regression line, upper and lower lines represent $95 \% \mathrm{Cl}$ of the linear regression line. The open circles represent scatters of the ghrelin levels and birht weight. 


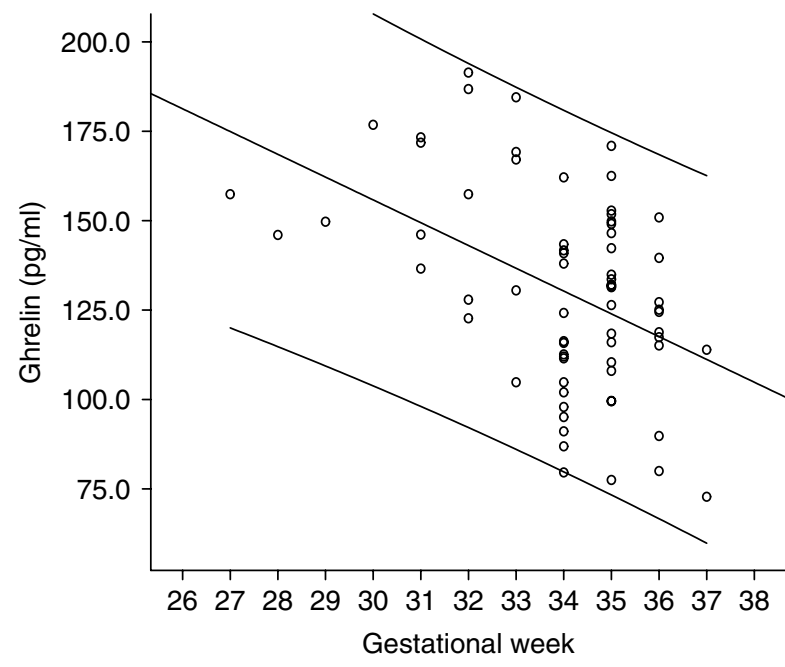

Figure 2 A negative correlation between active ghrelin level and gestational age using the Pearson correlation test $(r=-0.449$, $P<0.0001)$. The middle line represents the linear regression line, upper and lower lines represent $95 \% \mathrm{Cl}$ of the linear regression line. The open circles represent scatters of the ghrelin levels and gestational age.

physiological role in regulating growth and metabolism at $\geq 37$ weeks of gestation. Bellone et al. (11) also reported the lack of any direct relationship between cord ghrelin levels and anthropometric parameters in AGA infants born either at term or preterm. However, in the study by Chiesa et al. (26), total ghrelin concentration was higher in preterm SGA infants than in AGA preterms.

The study by Pirazzoli et al. (27) that investigated the total and active ghrelin levels in the cord blood of 98 healthy infants demonstrated no correlation between birth weight and active and total ghrelin levels.

In two other studies measuring total and active ghrelin levels in both preterm and term infants, Yokota et al. (22) reported that active ghrelin concentrations of 54 cord blood samples from full-term infants were inversely correlated with birth weight and that active ghrelin concentrations in SGA infants were significantly higher than those in AGA and LGA infants. Only five premature newborns were included in this study and they detected considerable levels of active ghrelin in these infants leading to the suggestion that the mechanism for the $n$-octanoylation of serine 3 is present during the premature stage. In the study by MartosMoreno et al. (21), higher number of preterm infants were included than in the previous study, and our study included infants between 22 and 36 weeks of gestation. Cord blood total ghrelin levels were higher in the SGA group (22 preterm and seven term infants) in this study and a negative correlation between total ghrelin levels and birth weight was observed in both term and preterm infant groups. However, acylated ghrelin levels did not differ between SGA and AGA infants with no correlations between acylated ghrelin levels and birth weight.

Two studies investigated active ghrelin levels in preterm infants with very low birth weight. The active ghrelin levels of SGA and AGA preterm infants in cord blood and at 2, 4, 6, and 8 weeks of age did not show any significant difference in the study by Shimizu et al. (23). Ohkawa et al. (28) also reported no significant difference in active ghrelin levels in cord blood or at 2, 4, 6, and 8 weeks of life between AGA and SGA preterm infants in a study population of 61 very low birth weight infants, and no correlation was observed between ghrelin levels and anthropometrical measures.

Our study was the first to report any correlation between active ghrelin levels and birth weight in preterm infants. Also, it was the first study to demonstrate that SGA preterm infants had higher levels of active ghrelin than those of their AGA counterparts.

The difference in our results in comparison with those of other studies might be attributable to the sampling time of ghrelin, which was in the immediate postnatal period since most of the other studies measured cord blood ghrelin. In three other studies, progressive increase in circulating total ghrelin levels in the days after birth has been demonstrated with significantly higher total ghrelin concentrations than those in cord blood $(13,18,29)$. In the study by Bellone et al. (29), total ghrelin levels in cord blood were not associated with birth weight, whereas on the fourth day of life, ghrelin levels in newborns negatively correlated to birth weight. The first days of life are characterized by a physiological weight decrease that reaches a nadir on the fourth day (29). This state of negative energy balance could have played a role in stimulating active ghrelin secretion contributing to our finding of a correlation between birth weight and active ghrelin level.

According to the literature and the findings of our study, it is obvious that even preterm infants are capable of producing ghrelin.

Our results are in contradiction with all of the studies evaluating active ghrelin levels in preterm infants. However, the majority of the studies evaluating total ghrelin levels in term and preterm SGA infants showed that higher circulating ghrelin levels were present in this infant population.

In contrast to the postulation of $\mathrm{Ng}$ et al. (16), our study led to the hypothesis that ghrelin might have already adopted its active physiological role in regulating growth and metabolism at a relatively early stage of gestation. However, its exact role in fetal and postnatal growth has not been clearly elucidated yet.

Iniguez et al. (30) reported that higher ghrelin levels or lower reductions in circulating levels following i.v. glucose were seen in SGA infants who showed greater infancy weight gain with postnatal catch-up growth. Accordingly, James et al. (31) postulated that lower cord ghrelin levels were associated with gradual weight gain from birth to 3 months of age. It has been shown that 
ghrelin levels increase in preterm infants early in the neonatal period $(13,23,29)$ and this increase is not inhibited by food intake $(13,29)$. So, ghrelin may play a physiological role in fetal adaptation to intrauterine malnutrition, and early changes in active ghrelin levels in the early neonatal period in preterm infants might suggest a possible role of active ghrelin in the adaptation of the neonatal metabolism to the extrauterine life with an anabolic drive during this growth and development period. Further investigations are needed to delineate the precise physiological role of acylated ghrelin in fetal and neonatal growth and metabolism since it is the acylated form that exerts neuroendocrine activity while the unacylated ghrelin that is present in serum at a higher level than the acylated ghrelin shares some nonendocrine actions like cardiovascular, metabolic, and antiproliferative effects (32).

In conclusion, our study is the first to demonstrate significantly higher circulating active ghrelin levels in preterm SGA infants and to report the negative correlation of active ghrelin with birth weight in the preterm infant population.

\section{Declaration of interest}

The authors declare that there is no conflict of interest that could be perceived as prejudicing the impartiality of the research reported.

\section{Funding}

This work was supported by the Turkish Pediatric Association (grant number 42, 2008).

\section{Author contribution statement}

Dr S Hamilcikan had primary responsibility for protocol development, patient screening, enrollment, outcome assessment, and preliminary data analysis. Dr $\mathrm{T}$ Erener contributed to the writing of the manuscript. Dr E Erginoz reanalyzed all statistical data. Dr M Vural also had responsibility for protocol development and supervised the design and execution of the study and performed the final data analyses. Dr B Ilikkan participated in the analytic framework of the study. Dr S Kavuncuoglu was responsible for patient screening and enrollment. Dr H Yildiz was also responsible for patient screening. Dr Y Perk participated in the development of the protocol and analytical framework for the study.

\section{Acknowledgements}

The authors thank the Turkish Pediatric Association for its financial support in obtaining the Active Ghrelin ELISA kit.

\section{References}

1 Ariyasu H, Takaya K, Tagami T, Ogawa Y, Hosada K, Akamizu T, Suda M, Koh T, Natsui K, Toyooka S, Shirakami G, Usui T, Shimatsu A, Doi K, Hosoda H, Kojima M, Kangawa K \& Nakao K. Stomach is a major source of circulating ghrelin and feeding state determines plasma ghrelin-like immunoreactivity levels. Journal of Clinical Endocrinology and Metabolism 200186 4753-4758. (doi:10.1210/jc.86.10.4753)
2 Van der Lely AJ, Tschop M, Heiman ML \& Ghigo E. Biological, physiological, pathophysiological, and pharmacological aspects of ghrelin. Endocrine Reviews 200425 426-457. (doi:10.1210/er. 2002-0029)

3 Ghigo E, Broglio F, Arvat E, Maccario M, Papotti M \& Muccioli G. Ghrelin: more than a natural GH secretagogue and/or an orexigenic factor. Clinical Endocrinology 200562 1-17. (doi:10. $1111 /$ j.1365-2265.2004.02160.x)

4 Fuglsang J, Sandager P, Moller N, Fisker S, Frystyk J \& Ovesen P. Peripartum maternal and foetal ghrelin, growth hormones, IGFs and insulin interrelations. Clinical Endocrinology $2006 \mathbf{6 4}$ 502-509. (doi:10.1111/j.1365-2265.2006.02498.x)

5 Sun Y, Ahmed S \& Smith RG. Deletion of ghrelin impairs neither growth nor appetite. Molecular and Cellular Biology 200323 7973-7981. (doi:10.1128/MCB.23.22.7973-7981.2003)

6 Wortley KE, Anderson KD, Garcia K, Murray JD, Malinova L, Liu R, Moncrieffe M, Thabet K, Cox HJ, Yancopoulos GD, Wiegand SJ \& Sleeman MW. Genetic deletion of ghrelin does not decrease food intake but influences metabolic fuel preference. PNAS 2004101 8227-8232. (doi:10.1073/pnas.0402763101)

7 Chanoine JP. Ghrelin in growth and development. Hormone Research 200563 129-138. (doi:10.1159/000084688)

8 Zhao TJ, Liang G, Li RL, Xie X, Sleeman MW, Murphy AJ, Valenzuela DM, Yancopoulos GD, Goldstein JL \& Brown MS. Ghrelin $\mathrm{O}$-acyltransferase (GOAT) is essential for growth hormonemediated survival of calorie-restricted mice. PNAS 2010107 7467-7472. (doi:10.1073/pnas.1002271107)

9 Sun Y, Butte NF, Garcia JM \& Smith RG. Characterization of adult ghrelin and ghrelin receptor knockout mice under positive and negative energy balance. Endocrinology 2008149 843-850. (doi:10.1210/en.2007-0271)

10 Cortelazzi D, Cappiello V, Morpurgo PS, Ronzoni S, Nobile De Santis MS, Beck-Peccoz P \& Spada A. Circulating levels of ghrelin in human fetuses. European Journal of Endocrinology 2003149 111-116. (doi:10.1530/eje.0.1490111)

11 Bellone S, Rapa A, Vivenza D, Rapa A, Vivenza D, Radetti G, Bellone J, Broglio F, Ghigo E \& Bona G. Circulating ghrelin levels in the newborn are positively associated with gestational age. Clinical Endocrinology 200460 613-617. (doi:10.1111/j.1365-2265. 2004.02014.x)

12 Önal E, Cinaz P, Atalay Y, Turkyilmaz C, Bideci A, Akturk A, Okumuş N, Unal S, Koç E \& Ergenekon E. Umbilical cord ghrelin concentrations in small- and appropriate-for-gestational age newborn infants: relationship to anthropometric markers. Journal of Endocrinology 2004180 267-271. (doi:10.1677/joe. $0.1800267)$

13 Kitamura S, Yokota I, Hosoda H, Kotani Y, Matsuda J, Naito E, Ito M, Kangawa K \& Kuroda Y. Ghrelin concentration in cord and neonatal blood: relation to fetal growth and energy balance. Journal of Clinical Endocrinology and Metabolism $2003 \mathbf{8 8}$ 5473-5477. (doi:10.1210/jc.2002-021350)

14 Lubchenco LO, Hansman C \& Boyd E. Intrauterine growth as estimated from live born birth-weight data at 24-42 weeks of gestation. Pediatrics 196332 793-798.

15 Ballard JL, Khoury JC, Wedig K, Wang L, Eilers-Walsman BL \& Lipp R. New Ballard Score, expanded to include extremely premature infants. Journal of Pediatrics $1991 \quad 119$ 417-423. (doi:10.1016/S0022-3476(05)82056-6)

16 Ng PC, Lee CH, Lam CWK, Chan IHS, Wong E \& Fok TF. Ghrelin in preterm and term newborns: relation to anthropometry, leptin and insulin. Clinical Endocrinology 200563 217-222. (doi:10.1111/j. 1365-2265.2005.02328.x)

17 Lanyi E, Varnagy A, Kovacs KA, Csermely T, Szasz M \& Szabo I. Ghrelin and acyl ghrelin in preterm infants and maternal blood: relationship with endocrine and anthropometric measures. European Journal of Endocrinology 2008158 27-33. (doi:10. 1530/EJE-07-0410)

18 Soriano-Guillen L, Barrios V, Chowen JA, Sánchez I, Vila S, Quero J \& Argente J. Ghrelin levels from fetal life through early adulthood: 
relationship with endocrine and metabolic and anthropometric measures. Journal of Pediatrics 2004144 30-35. (doi:10.1016/j. jpeds.2003.08.050)

19 Farquhar J, Heiman M, Wong ACK, Wach R, Chessex P \& Chanoine JP. Elevated umbilical cord ghrelin concentrations in small for gestational age neonates. Journal of Clinical Endocrinology and Metabolism 200388 4324-4327. (doi:10.1210/jc.2003030265)

20 Chanoine JP, Yeung LP, Wong AC \& Birmingham CL. Immunoreactive ghrelin in human cord blood: relation to anthropometry, leptin, and growth hormone. Journal of Pediatric Gastroenterology and Nutrition 200235 282-286. (doi:10.1097/00005176200209000-00009)

21 Martos-Moreno G, Barrios V, Saenz de Pipaon M, Pozo J, Dorronsoro I, Martinez-Biarge M, Quero J \& Argente J. Influence of prematurity and growth restriction on the adipokine profile, IGF-1, and ghrelin levels in cord blood: relationship with glucose metabolism. European Journal of Endocrinology 2009161 381-389. (doi:10.1530/EJE-09-0193)

22 Yokota I, Kitamura S, Hosoda H, Kotani Y \& Kangawa K. Concentration of the $n$-octanoylated active form ghrelin in fetal and neonatal circulation. Endocrine Journal 200552 271-276. (doi:10.1507/endocrj.52.271)

23 Shimizu T, Kitamura T, Yoshikawa N, Suganuma H, Hisata K, Tanaka K, Shinohara K \& Yamashiro Y. Plasma levels of active ghrelin until 8 weeks after birth in preterm infants: relationship with anthropometric and biochemical measures. Archives of Disease in Childhood. Fetal and Neonatal Edition 2007 92 291-292. (doi:10.1136/adc.2005.092379)

24 Kyriakakou M, Malamitsi-Puchner A, Mastorakos G, Boutsikou T, Hassiakos D, Papassotiriou I \& Kanaka-Gantenbein C. The role of IGF-1 and ghrelin in the compensation of intrauterine growth restriction. Reproductive Sciences 200916 1193-1200. (doi:10. 1177/1933719109344629)

25 Ramirez FM, Sabanero G, Gutierez GR \& Malacara JM. Ghrelin in small-for-gestational (SGA) newborn babies: a cross-sectional study. Clinical Endocrinology 2009 70 41-46. (doi:10.1111/j. 1365-2265.2008.03278.x)

26 Chiesa C, Osborn JF, Haass C, Natale F, Spinelli M, Scapillati E, Spinelli A \& Pacifico L. Ghrelin, leptin, IGF-1, IGFBP-3, and insulin concentrations at birth: is there a relationship with fetal growth and neonatal anthropometry? Clinical Chemistry $2008 \mathbf{5 4}$ 550-558. (doi:10.1373/clinchem.2007.095299)

27 Pirazzoli P, Lanari M, Zucchini S, Gennari M, Pagotto U, De Lasio R, Pasquali R, Cassio A, Cicognani A \& Cacciari E. Active and total ghrelin concentrations in the newborn. Journal of Pediatric Endocrinology \& Metabolism 200518 379-384. (doi:10.1515/ JPEM.2005.18.4.379)

28 Ohkawa N, Shoji H, Kitamura T, Suganuma H, Yoshikawa N, Suzuki M, Lee T, Hisata K \& Shimizu T. IGF-1, leptin active ghrelin levels in very low birth weight infants during the first 8 weeks of life. Acta Paediatrica 201099 37-41. (doi:10.1111/j.1651-2227. 2009.01516.x)

29 Bellone S, Baldelli R, Radetti G, Rapa A, Vivenza D, Petri A, Savastio S, Zaffaroni M, Broglio F, Ghigo E \& Bona G. Ghrelin secretion in preterm neonates progressively increases and is refractory to the inhibitory effect of food intake. Journal of Clinical Endocrinology and Metabolism 200691 1929-1933. (doi:10. 1210/jc.2005-2185)

30 Iniguez G, Ong K, Pena V, Avila A, Dunger D \& Mericq V. Fasting and post-glucose ghrelin levels in SGA infants: relationships with size and weight gain at one year of age. Journal of Clinical Endocrinology and Metabolism 200287 5830-5833. (doi:10. 1210/jc.2002-021206)

31 James RJA, Drewett RF \& Cheetham TD. Low cord ghrelin levels in term infants are associated with low weight gain over the 3 months of life. Journal of Clinical Endocrinology and Metabolism 200489 3847-3850. (doi:10.1210/jc.2003-032167)

32 Broglio F, Gottero C, Prodam F, Gauna C, Muccioli G, Papotti M, Abribat T, Van Der Lely AJ \& Ghigo E. Non-acylated ghrelin counteracts the metabolic but not the neuroendocrine response to acylated ghrelin in humans. Journal of Clinical Endocrinology and Metabolism 200489 3062-3065. (doi:10.1210/jc.2003031964)

Received 11 July 2011

Revised version received 15 November 2011

Accepted 5 December 2011 